DOI: 10.12731/wsd-2017-4-2-20-31

УДК 616-006

\title{
ДИНАМИКА \\ КЛИНИКО-ИММУНОЛОГИЧЕСКИХ ПОКАЗАТЕЛЕЙ ОСТРОГО НЕЛИМФОБЛАСТНОГО ЛЕЙКОЗА
}

\section{Смирнова О.В., Манчук В.Т.}

Целью исследования было изучение особенностей клинических проявлений, иммунопатогенеза и механизмов нарушения метаболического статуса лимфоцитов у больных острым миелобластным лейкозом (ОМЛ). На стадии острого дебюта и ремиссии ОМЛ развивается Т-клеточный иммунодефицит, на стадии повторного рецидива - комбинированный иммунодефицит с поражением T- и В-систем иммунитета. Особенностью ОМЛ является истощение содержания NK-клеток, которое способствует прогрессированию заболевания и развитию рецидива. На всех стадиях ОМЛ наблюдается выраженное уменьшение интенсивности внутриклеточных метаболических процессов лимфоцитов, снижаются митохондриальный транспорт, гликолиз, метаболизм в лимонном ичикле. Особенностью острого дебюта и ремиссии ОМЛ является снижение перекисных процессов в лимфоцитах. При повторном рецидиве-восстанавливаются перекисные проиессы в лимфоцитах, однако, снижается внутриклеточный липидный катаболизм.

Ключевые слова: острый миелобластный лейкоз; иммунитет; ферментыл.

\section{DYNAMICS OF CLINICAL AND IMMUNOLOGICAL INDICATORS OF ACUTE NON-LYMPHOBLASTIC LEUKEMIA}

\section{Smirnova O.V., Manchuk V.T.}

The aim of the study was to study the features of clinical manifestations, immunopathogenesis and mechanisms of metabolic status of lymphocytes in patients with acute non-lymphoblastic leukemia (ONLL). At the stage of primary attack and remission of ONLT, T-cell immunodeficiency develops, at the stage of repeated relapse-combined immunodeficiency with defeat of $T$ - and 
B-systems of immunity. A feature of ONLL is the depletion of the content of NK cells, which contributes to the progression of the disease and the development of relapse. At all stages of ONLL, a marked decrease in the intensity of intracellular metabolic processes of lymphocytes is observed, mitochondrial transport, glycolysis, and metabolism in the lemon cycle decrease. A feature of the primary attack and remission of ONLL is the reduction of peroxide processes in lymphocytes. With repeated relapse, peroxide processes in lymphocytes are restored, however, intracellular lipid catabolism decreases.

Keywords: acute myeloblast leukemia; immunity; enzymes.

Острые лейкозы - тяжелые онко-гематологические заболевания. В настоящее время повысилась выявляемость острыми лейкозами, в связи с этим увеличилось число госпитализаций по этому поводу [1, с. 84-89; 2 , c. 235-237]. Этиология заболевания в большинстве случаев остается неизвестной [1, с. 84-89; 2, с. 235-237]. Известны предикторы болезни, которые способствуют не только возникновению, но и прогрессированию острых лейкозов. К ним относятся РНК-ретровирусы, химиотерапия, радиотерапия, радиационное излучение, врожденные и приобретенные хромосомные нарушения, курение, химические канцерогенные вещества, наследственность [3, с. 37-43; 4, с. 129].

В патогенезе развития острых лейкозов большую роль играет мутация гемопоэтической клетки с нарушением ее пролиферации, дифференцировки и апоптоза и последующим накоплением опухолевого субстрата. Патологическим опухолевым клоном при острых лейкозах являются бластные клетки, не способные к дальнейшим превращениям и нормальному функционированию, что вызывает прогрессирование онкологического процесса и появление клинических симптомов.

Уменьшение реактивности иммунной системы больного является одним из провоцирующих механизмов в прогрессировании заболевания. Известно, что появление иммунодефицитного состояния вызывает развитие острого лейкоза, при этом сама злокачественная опухоль, выделяя активные факторы, индуцирует не только развитие иммунной депрессии, но и модифицирует клетки иммунной системы. У больных злокачественными гематологическими заболеваниями уменьшается количество эффекторных клеток, нарушается их функция и пролиферативный индекс, цитокиновая регуляция. В зависимости от механизмов иммунного реагирования характеризуются особенности течения гемобластозов [5, с. $185-$ 189 ; 6, c. $403-408$; 7, c. 280-285]. 
Функционирование иммунной системы зависит от особенностей и выраженности метаболических процессов в ее клетках. Ферменты окислительно-восстановительных реакций используются для оценки биохимических процессов в лимфоцитах, потому что они реализуют основные реакции внутриклеточного метаболизма и отвечают за объединение всех метаболических обменов [8, с. 63-64]. В связи с этим, целью настоящего исследования было изучение клинических симптомов, особенностей иммунологического и метаболического статусов лимфоцитов у больных острым миелобластным лейкозом (ОМЛ).

\section{Материалы и методы}

В группе исследования были 100 больных ОМЛ, в стадии острого дебюта - 30 пациентов, в стадии полной ремиссии после проведенного лечения - 49 больных, в стадии повторного рецидива - 21 человек (классификация лейкозов по ФАБ (1976-1980) и Воробьеву А.И. (1985)).

Для стадии острого дебюта характерно первое проявление заболевания с количеством бластов в костном мозге $25 \%$ и более. Полная ремиссия после лечения у больных диагностировалась при выявлении в миелограмме не более 5\% бластных клеток при нормальной его клеточности, в ликворе отсутствовали лейкемические клетки. Повторный рецидив выявлялся при обнаружении в показателях костного мозга более $25 \%$ бластов после достигнутой ранее ремиссии. Контрольную группу составили 125 практически здоровых добровольцев. Сравнительное исследование проводилось с разрешения этического комитета НИИ МПС ФИЦ КНЦ СО РАН, при этом информированное согласие на обследование подписывал каждый участник исследования.

Популяционный и субпопуляционный состав лимфоцитов периферической крови оценивали с помощью метода непрямой иммунофлуоресценции с использованием моноклональных антител к CD3, CD4, CD8, CD16, CD19, HLA-DR (TOO «Сорбент» г. Москва). Для дополнительной характеристики Т-клеточного звена иммунной системы вычисляли иммунорегуляторный $\left(\mathrm{CD} 4^{+} / \mathrm{CD} 8^{+}\right)$, лейко-Т-клеточный (Лейкоциты $\left./ \mathrm{CD}^{+}\right)$, лейко-В-клеточный (Лейкоциты/CD19+) индексы, а также индекс активации T-лимфоцитов $\left(\mathrm{HLA}_{\mathrm{DLR}}^{+} / \mathrm{CD} 19^{+}\right)$. Концентрацию иммуноглобулинов класса $\mathrm{A}, \mathrm{M}$ и $\mathrm{G}$ в сыворотке крови определяли иммуноферментным методом, используя тест-системы ЗАО «Вектор-Бест» (г. Новосибирск). Состояние гуморального иммунитета характеризовали также уровнем относительного синтеза $\operatorname{IgA}\left(\operatorname{IgA} / \mathrm{CD} 19^{+}\right), \operatorname{IgM}\left(\operatorname{IgM} / \mathrm{CD} 19^{+}\right)$и $\operatorname{IgG}\left(\operatorname{IgG} / \mathrm{CD} 19^{+}\right)$. 
Биолюминесцентное определение активности НАД(Ф)-зависимых дегидрогеназ проводили по ранее разработанным методикам [9, с. 23-25]. Данным методом определялась активность следующих ферментов: глюкозо-6-фосфатдегидрогеназы (ГбФДГ), глицерол-3-фосфатдегидрогеназы (ГЗФДГ), малик-фермента (НАДФМДГ), НАД- и НАДН-зависимой реакции лактатдегидрогеназы (ЛДГ и НАДН-ЛДГ), НАД- и НАДН-зависимой реакции малатдегидрогеназы (МДГ и НАДН-МДГ), НАДФ- и НАДФН-зависимой глутаматдегидрогеназы (НАДФГДГ и НАДФН-ГДГ), НАД- и НАДН-зависимой глутаматдегидрогеназы (НАДГДГ и НАДНГДГ), НАД- и НАДФ-зависимых изоцитратдегидрогеназ (НАДИЦДГ и НАДФИЦДГ, соответственно) и глутатионредуктазы (ГР). Активность дегидрогеназ в лимфоцитах крови выражали в ферментативных единицах (1 $\mathrm{E}=1$ мкмоль/мин) на $10^{4}$ клеток).

По результатам исследования была сформирована база данных в электронных таблицах MS Excel 2000, на основе которой производился статистический анализ методами описательной статистики с t-критерием Стьюдента, непараметрическим с использованием точных критериев Манна-Уитни, используя пакет прикладных программ Statistica 8.0. Для решения задач системного анализа использовали дискриминантный анализ и нейросетевой классификатор. Дискриминантный анализ проводился по методу Forward stepwise (Tolerance $=0,010, \mathrm{~F}$ to enter $=2,30, \mathrm{~F}$ to remove $=1,50$, Number of steps $=25)$. Количество заданных шагов соответствовало числу изучаемых параметров иммунного статуса.

\section{Результаты исследования и их обсуждение}

У всех больных ОМЛ иммунофенотипировался М2-вариант. Большинство больных (96\%) выписались после проведенной терапии на амбулаторное лечение. У большинства больных $(79,8 \%)$ выявлялся многоклеточный острый лейкоз, количество бластов было 95,0 $2,1 \%$.

У большинства больных ОМЛ (53\%) заболевание начиналось с появления сочетанных клинических симптомов, при поступлении обнаруживались лихорадка более $38^{\circ} \mathrm{C}(70 \%)$, выраженный синдром опухолевой интоксикации (99\%), геморрагические проявления (62\%), и инфекционные осложнения (66\%). Увеличение печение диагностировалось у половины больных ОМЛ (46\%). Однако генерализованное увеличение лимфатических узлов выявлялось всего у 17\% больных ОМЛ. Ответ на проводимую патогенетическую терапию была получена у 99\% пациентов. Постхимиотерапевтические осложнения в виде агранулоцитоза (93\%) и панцитопении 
(59\%) выявлялись у большинства больных М2-ОМЛ, при этом диагностировались признаки анемии (84\%), геморрагических проявлений $(35 \%)$ и инфекционные осложнения $(60 \%)[10,11]$.

Большинство работ посвящены иммунофенотипированию острых лейкозов с последующей персонифицированной терапией. Мы изучили особенности клеточного и гуморального звеньев иммунитета с активностью метаболических ферментов в зависимости от стадии заболевания.

В целом, при исследовании характеристик иммунного статуса больных ОМЛ наиболее существенные изменения диагностируются у больных при повторном рецидиве заболевания, что свидетельствует о предшествующем неэффективном иммунном ответе (табл. 1).

Таблица 1.

Параметры иммунного статуса у больных на разных стадиях ОМЛ (Me, $\mathrm{C}_{25}-\mathrm{C}_{75}$ )

\begin{tabular}{|c|c|c|c|c|c|c|c|c|}
\hline \multirow[t]{2}{*}{ Показатели } & \multicolumn{2}{|c|}{$\begin{array}{c}\text { Контроль, } \mathrm{N}=125 \\
1\end{array}$} & \multicolumn{2}{|c|}{$\begin{array}{l}\text { Атака, } \mathrm{N}=30 \\
2\end{array}$} & \multicolumn{2}{|c|}{$\begin{array}{l}\text { Ремиссия, } \mathrm{N}=49 \\
3 \\
\end{array}$} & \multicolumn{2}{|c|}{$\begin{array}{c}\text { Рецидив, } \mathrm{N}=21 \\
4\end{array}$} \\
\hline & $\mathrm{Me}$ & $\mathrm{C}_{25}-\mathrm{C}_{75}$ & $\mathrm{Me}$ & $\mathrm{C}_{25}-\mathrm{C}_{75}$ & $\mathrm{Me}$ & $\mathrm{C}_{25}-\mathrm{C}_{75}$ & $\mathrm{Me}$ & $\mathrm{C}_{25}-\mathrm{C}_{75}$ \\
\hline \multirow{2}{*}{$\begin{array}{l}\text { Лейкоциты, } \\
(10 \% \text { /л) }\end{array}$} & 5,7 & $4,9-7,8$ & 6,42 & $2,51-9,63$ & 4,52 & $3,17-6,47$ & 3,12 & $1,53-6,08$ \\
\hline & & & & & \multicolumn{2}{|c|}{$\mathrm{p}_{1}<0,001 \mathrm{p}_{2}<0,05$} & \multicolumn{2}{|c|}{$\mathrm{p}_{1}<0,001 \mathrm{p}_{2}<0,05$} \\
\hline \multirow{2}{*}{$\begin{array}{l}\text { Лимфоциты, } \\
(\%)\end{array}$} & 38,00 & $31,0-45,00$ & 44,00 & $25,00-70,00$ & 28,00 & $24,00-43,00$ & 43,00 & $31,00-79,00$ \\
\hline & & & & & \multicolumn{2}{|r|}{$\mathrm{p}_{1}<0,01$} & \multicolumn{2}{|r|}{$\mathrm{p}_{3}<0,05$} \\
\hline \multirow{2}{*}{$\mathrm{CD}^{+},(\%)$} & 68,0 & $61,00-73,00$ & 57,00 & $40,0-65,00$ & 58,00 & $40,00-65,00$ & 56,00 & $47,00-60,0$ \\
\hline & & & \multicolumn{2}{|c|}{$\mathrm{p}_{1}<0,001$} & \multicolumn{2}{|r|}{$\mathrm{p}_{1}<0,001$} & \multicolumn{2}{|c|}{$\mathrm{p}_{1}<0,001$} \\
\hline \multirow{2}{*}{$\mathrm{CD}^{+},(\%)$} & \begin{tabular}{|l|}
44,0 \\
\end{tabular} & $35,0-49,0$ & 35,0 & $29,0-40,0$ & 32,0 & $26,5-41,0$ & 29,0 & $19,0-43,0$ \\
\hline & & & \multicolumn{2}{|r|}{$\mathrm{p}_{1}<0,01$} & \multicolumn{2}{|r|}{$\mathrm{p}_{1}<0,001$} & \multicolumn{2}{|r|}{$\mathrm{p}_{1}<0,01$} \\
\hline \multirow{2}{*}{$\mathrm{CD}^{+},(\%)$} & 27,0 & $20,0-34,0$ & 25,0 & $20,0-33,0$ & 24,0 & $16,0-31,0$ & 30,0 & $18,0-33,0$ \\
\hline & & & & & \multicolumn{2}{|r|}{$\mathrm{p}_{1}<0,05$} & & \\
\hline \multirow{2}{*}{$\mathrm{CD} 16^{+},(\%)$} & 20,0 & $17,0-23,0$ & 22,0 & $15,0-31,0$ & 13,0 & $8,0-23,5$ & 12,0 & $5,0-19,5$ \\
\hline & & & & & \multicolumn{2}{|r|}{$\mathrm{p}_{1,2}<0,05$} & \multicolumn{2}{|c|}{$\mathrm{p}_{1}<0,01 \mathrm{p}_{2}<0,05$} \\
\hline $\mathrm{CD} 9^{+},(\%)$ & 13,5 & $9,0-16,0$ & 12,0 & $9,0-15,0$ & 13,0 & $7,0-16,0$ & 11,0 & $7,0-29,0$ \\
\hline HLA-DR $^{+},(\%)$ & 15,0 & $12,0-20,0$ & 15,0 & $9,0-25,0$ & 15,0 & $9,0-24,0$ & 11,0 & $7,0-33,0$ \\
\hline $\mathrm{CD}^{+} / \mathrm{CD}^{+}$ & 1,52 & $1,13-1,95$ & 1,30 & $1,00-1,70$ & 1,50 & $0,90-1,95$ & 1,30 & $0,90-1,70$ \\
\hline \multirow{2}{*}{$\operatorname{IgA}$, (г/л) } & 1,91 & $1,33-3,20$ & 2,12 & $0,62-4,35$ & 1,57 & $0,68-3,70$ & 0,96 & $0,56-2,49$ \\
\hline & & & & & & & \multicolumn{2}{|r|}{$\mathrm{p}_{1}<0,01$} \\
\hline \multirow{2}{*}{$\operatorname{IgM,~(г/л)~}$} & 1,20 & $0,50-1,80$ & 1,3 & $0,60-1,90$ & 1,02 & $0,64-2,00$ & 0,61 & $0,40-0,91$ \\
\hline & & & & & & & \multicolumn{2}{|c|}{$\mathrm{p}_{1,2,3}<0,05 \mathrm{p}_{3}<0,01$} \\
\hline \multirow{2}{*}{$\operatorname{IgG},(г / л)$} & 10,30 & $8,18-14,12$ & 13,68 & $6,70-32,50$ & 7,60 & $5,90-14,52$ & 6,12 & $3,89-7,33$ \\
\hline & & & & & \multicolumn{2}{|r|}{$\mathrm{p}_{1,2}<0,05$} & \multicolumn{2}{|c|}{$\mathrm{p}_{1.2}<0,001$} \\
\hline
\end{tabular}

Примечание: $\mathrm{p}_{1}$ - статистически достоверные различия с показателями контрольной группы; $\mathrm{p}_{2}$ - -//- с показателями больных на стадии острого дебюта; $\mathrm{p}_{3}-$-//- с показателями больных на стадии ремиссии ОМЛ. 
Состояние клеточного звена иммунитета у больных М2-вариантом ОМЛ при первичной атаке характеризуется снижением относительного количества pan-маркеров Т-лимфоцитов и Т-хелперов, что указывает не только на развитие иммунодефицитного состояния, но и на неполноценность Т-хелперного звена, приводящее к неэффективности и клеточного, и гуморального звеньев иммунитета. При исследовании гуморального звена иммунитета никаких изменений не найдено. При изучении особенностей метаболического статуса лимфоцитов крови у больных при первичной атаке ОМЛ выявляется снижение активности аэробной реакции ЛДГ, что вероятно, свидетельствует об усиленном напряжении метаболизма митохондриального компартмента (табл. 2).

Таблица 2.

Параметры метаболического статуса в лимфоцитах в крови у больных на разных стадиях ОМЛ (Me, $\mathrm{C}_{25}-\mathrm{C}_{75}$ )

\begin{tabular}{|c|c|c|c|c|c|c|c|c|}
\hline \multirow[t]{2}{*}{ Показатели } & \multicolumn{2}{|c|}{$\begin{array}{c}\text { Контроль, } \mathrm{N}=125 \\
1\end{array}$} & \multicolumn{2}{|c|}{$\begin{array}{c}\text { Атака, } \mathrm{N}=25 \\
2\end{array}$} & \multicolumn{2}{|c|}{$\begin{array}{l}\text { Ремиссия, } \mathrm{N}=36 \\
3\end{array}$} & \multicolumn{2}{|c|}{$\begin{array}{c}\text { Рецидив, N=17 } \\
4\end{array}$} \\
\hline & $\mathrm{Me}$ & $\mathrm{C}_{25}-\mathrm{C}_{75}$ & $\mathrm{Me}$ & $\mathrm{C}_{25}-\mathrm{C}_{75}$ & $\mathrm{Me}$ & $\mathrm{C}_{25}-\mathrm{C}_{75}$ & $\mathrm{Me}$ & $\mathrm{C}_{25}-\mathrm{C}_{75}$ \\
\hline ГбФДГ & 4,32 & $0,90-13,87$ & 5,27 & $0,93-10,15$ & 6,23 & $0,042-66,53$ & 3,74 & $1,69-27,90$ \\
\hline \multirow{2}{*}{ ГЗФДГ } & 0,63 & $0,00-1,96$ & 0,01 & $0,00-0,88$ & 0,05 & $0,00-2,37$ & 0,00 & $0,00-0,02$ \\
\hline & & & & & & & \multicolumn{2}{|c|}{$\mathrm{p}_{1,3}<0,01$} \\
\hline \multirow{2}{*}{ Лдг } & 38,43 & $14,85-98,98$ & 4,80 & $0,39-15,20$ & 10,50 & $0,75-28,17$ & 2,81 & $0,04-12,62$ \\
\hline & & & \multicolumn{2}{|r|}{$\mathrm{p}_{1}<0,001$} & \multicolumn{2}{|c|}{$\mathrm{p}_{1}<0,001$} & \multicolumn{2}{|c|}{$\mathrm{p}_{1}<0,001$} \\
\hline НАДФМДГ & 2,84 & $0,64-12,75$ & 2,35 & $0,13-20,89$ & 3,10 & $0,99-22,24$ & 1,31 & $0,25-6,25$ \\
\hline НАДФГДГ & 0,59 & $0,00-2,56$ & 0,22 & $0,00-2,17$ & 0,47 & $0,00-1,63$ & 0,10 & $0,00-0,62$ \\
\hline \multirow{2}{*}{ НАДФИЦДГ } & 33,33 & $14,70-63,63$ & 1,25 & $0,40-4,07$ & 1,19 & $0,47-5,60$ & 1,76 & $0,54-3,17$ \\
\hline & & & \multicolumn{2}{|r|}{$\mathrm{p}_{1}<0,001$} & \multicolumn{2}{|r|}{$\mathrm{p}_{1}<0,001$} & \multicolumn{2}{|c|}{$\mathrm{p}_{1}<0,001$} \\
\hline \multirow{2}{*}{ МдГ } & 70,43 & $17,99-144,34$ & 22,65 & $17,63-40,39$ & 26,66 & $10,32-48,79$ & 22,40 & $19,41-41,23$ \\
\hline & & & \multicolumn{2}{|r|}{$\mathrm{p}_{1}<0,01$} & \multicolumn{2}{|r|}{$\mathrm{p}_{1}<0,001$} & \multicolumn{2}{|r|}{$\mathrm{p}_{1}<0,05$} \\
\hline НАДГДГ & 5,64 & 16,76 & 3,63 & $0,82-10,42$ & 3,65 & $1,19-8,85$ & 4,73 & $0,97-9,53$ \\
\hline \multirow{2}{*}{ НАДИЦДГ } & 4,05 & $1,00-12,93$ & 0,45 & $0,00-2,43$ & 0,04 & $0,00-0,96$ & 0,69 & $0,00-4,05$ \\
\hline & & & \multicolumn{2}{|r|}{$\mathrm{p}_{1}<0,001$} & \multicolumn{2}{|r|}{$\mathrm{p}_{1}<0,001$} & \multicolumn{2}{|r|}{$\mathrm{p}_{1}<0,01$} \\
\hline \multirow{2}{*}{ НАДН-ЛДГ } & 72,87 & $8,56-196,34$ & 0,19 & $0,00-113,67$ & 27,93 & $0,00-312,22$ & 6,77 & $0,00-63,31$ \\
\hline & & & \multicolumn{2}{|r|}{$\mathrm{p}_{1}<0,01$} & & & \multicolumn{2}{|r|}{$\mathrm{p}_{1}<0,01$} \\
\hline НАДН-МДГ & 128,37 & $35,45-357,11$ & 72,01 & $28,37-246,80$ & 126,80 & $43,12-359,03$ & 101,59 & $22,01-232,78$ \\
\hline \multirow{2}{*}{ ГР } & 19,64 & $1,67-113,62$ & 8,66 & $0,00-41,03$ & 9,54 & $0,00-26,83$ & 47,43 & $8,63-79,63$ \\
\hline & & & \multicolumn{2}{|r|}{$\mathrm{p}_{1}<0,05$} & \multicolumn{2}{|r|}{$\mathrm{p}_{1}<0,05$} & \multicolumn{2}{|c|}{$\mathrm{p}_{2,3}<0,01$} \\
\hline НАДН-ГДГ & 49,94 & $13,93-83,36$ & 24,12 & $7,75-62,03$ & 33,83 & $1,34-104,43$ & 24,12 & $9,82-82,80$ \\
\hline НАДФН-ГДГ & 52,87 & $29,59-84,88$ & 91,71 & $16,62-126,75$ & 86,80 & $23,81-167,73$ & 94,23 & $30,90-254,39$ \\
\hline
\end{tabular}

Примечание: то же, что и для табл. 1. 
Снижение интенсивности терминальных реакций гликолиза и уровня концентрации интермедиатов для цикла Кребса доказывается выявленной пониженной активностью ЛДГ и НАДН-ЛДГ. Снижается уровень реакции цикла Кребса НАДФ-зависимой изоцитратдегидрогеназы у больных на стадии острого дебюта относительно контроля, вероятно, этим объясняется недостаточность биохимических реакций в митохондриях. Нарушение интенсивности субстратного потока по лимонному циклу объясняется уменьшенной активностью ферментов НАДИЦДГ и МДГ в лимфоцитах. Однако у данных больных выявляется нормальная активность НАДФНГДГ, что свидетельствует о ненарушенном аминокислотном обмене, недостаточность реакций цикла Кребса не приводит к его изменению. Еще одна интересная особенность - пониженная активность фермента глутатионредуктазы, ведущего фермента глутатионового звена антиоксидантной защиты. Уменьшение активности данного фермента у больных М2-вариантом ОМЛ на стадии острого дебюта, вероятно, связано с недостаточностью антиоксидантной защиты в целом, и глутатионового звена, в частности.

В модели нейросетевого классификатора на стадии острого дебюта обнаружена взаимосвязь между содержанием бластных клеток в костном мозге и процентным уровнем рап-маркеров Т-лимфоцитов, что свидетельствует о том, что опухолевым субстратом при остром лейкозе являются бласты, от количества, которых зависит не только стадия заболевания, но и функционирование всех Т-лимфоцитов.

На стадии полной ремиссии больных М2-вариантом ОМЛ выявляется лейкопения, снижение относительных и абсолютных показателей Т-клеточного звена иммунитета, NK-клеток, B-лимфоцитов с нарушением процессов активации. Данное состояние характеризуется угнетением всех звеньев иммунитета. Уменьшение количества Т- и В-лимфоцитов в крови подтверждается повышением величин лейко-Т- и лейко-В-клеточных коэффициентов и увеличением индекса активации Т-лимфоцитов. При изучении гуморального звена иммунитета обнаружено снижение содержания $\mathrm{IgG}$ в крови. У больных в стадии полной ремиссии ОМЛ восстанавливается активность фермента НАДН-ЛДГ, при этом активность фермента ЛДГ остается сниженной. Таким образом, у данных больных выявляется пониженная интенсивность гликолиза, в остальном изменения метаболического статуса лимфоцитов соответствуют изменениям больных на стадии острого дебюта. Следовательно, выраженные изменения иммунного статуса коррелируют с обнаруженными нарушениями метаболизма лимфоцитов, что способствует их взаимное отягощение. 
В модели нейросетевого классификатора на стадии полной ремиссии обнаружена корреляционная связь между содержанием бластных клеток в костном мозге и абсолютными количествами лимфоцитов, Т-клеток, цитотоксических лимфоцитов, что свидетельствует о влиянии опухолевых бластных клеток на все показатели клеточного звена иммунитета.

При повторном рецидиве ОМЛ состояние клеточного иммунитета проявляется в виде лейкопении, лимфопении, снижение относительных и абсолютных показателей Т-клеточного звена иммунитета, NK-клеток, В-лимфоцитов с нарушением процессов активации. При изучении гуморального звена иммунитета выявляется снижение $\operatorname{IgA}, \operatorname{IgM}, \operatorname{IgG}$.

При изучении метаболического статуса больных М2-вариантом ОМЛ при повторном рецидиве выявляется уменьшение переноса продуктов липидного катаболизма на восстановительно-окислительные реакции гликолиза, за счет уменьшения активности ГЗФДГ. Снижение активности гликолиза приводит к его ингибированию, что подтверждается пониженной активностью анаэробной реакции ЛДГ. Уменьшена активность НАДНЛДГ, что свидетельствует об ингибировании гликолиза на терминальных стадиях. Уменьшена активность аэробной реакции ЛДГ в лимфоцитах, следовательно, в митохондрии поступает пониженное количество субстрата - пирувата, что, вероятно, вызывает ингибирование всех ферментативных реакций цикла трикарбоновых кислот. Нарушается субстратный поток по лимонному циклу (снижены НАДИЦДГ и МДГ). Снижена активность вспомогательной дегидрогеназной реакции (НАДФИЦДГ). Однако у больных ОМЛ на стадии повторного рецидива восстанавливается активность глутатионредуктазы, что свидетельствует об активации антиоксидантной защиты и нормализации глутатионового звена.

В модели нейросетевого предиктора обнаружена корреляционная связь между количеством бластных клеток в костном мозге и абсолютным количеством лейкоцитов крови, лейко-В-клеточным коэффициентом и содержанием IgA, что свидетельствует о более значительных нарушениях в иммунной системе: в клеточном и гуморальном звеньях иммунитета.

Дискриминантный системный анализ группы больных ОМЛ и контрольной группы обнаружил, что наиболее значимыми предикторами иммунного статуса в зависимости от стадии ОМЛ являются уровни относительного содержания Т- и В-лимфоцитов, абсолютные количества T-хелперов, NK- и В-лимфоцитов, лейко-Т-клеточный коэффициент, индекс активации T-лимфоцитов, содержание $\mathrm{IgG}$ и уровень относительного синтеза IgA. Только 82,5\% лиц из всех рассмотренных случаев были рас- 
познаны классификатором, как верные. Выявленные дискриминантным анализом изменения свидетельствуют о глубоких нарушениях в клеточном и гуморальном звеньях иммунитета у больных М2-вариантом ОМЛ.

\section{Заключение}

Выявленные иммунологические и метаболические характеристики М2-варианта ОМЛ позволяют провести дифференциальную диагностику стадий заболевания. Наиболее существенные изменения обнаруживаются на стадии повторного рецидива. Для стадии острого дебюта и полной ремиссии характерно развитие Т-клеточного иммунодефицита, для стадии повторного рецидива - комбинированный Т- и В-клеточный иммунодефицит. На стадиях полной ремиссии и повторного рецидива выявляется уменьшение количества NK-клеток, следовательно, выявляются выраженные нарушения врожденного и приобретенного клеточного иммунитета. Для всех стадии М2-варианта ОМЛ характерно угнетение биохимических, метаболических процессов, гликолиза, метаболизма в лимонном цикле, транспорт в митохондриальном компартменте, при этом на стадии острого дебюта и полной ремиссии нарушается, а на стадии повторного рецидива восстанавливается фермент глутатионового звена антиоксидантной защиты. Нарушения иммунной системы, метаболизма лимфоцитов и недостаточность антиоксидантной защиты являются важнейшими механизмами прогрессирования острого нелимфобластного лейкоза М2-варианта.

\section{Список литературы}

1. Василевский М.Г., Камарли 3.П. Статистика и проблемы гемобластозов // Вестник Кыргызско-Российского славянского университета. 2007. Т.7. №9. С. 84-89.

2. Воробьев А.И. Руководство по гематологии в 3-х томах. Т.1. М.: Ньюдиамед, 2002. 280 c.

3. Галстян Г.М., Кесельман С.А., Городецкий В.М. и др. Сочетанное проведение химиотерапии гемобластозов и терапии острой дыхательной недостаточности в реанимационных условиях // Терапевтический архив. 2009. №12. С. $37-43$.

4. Ковалева Л.Г. Острые лейкозы. М.: Медицина, 1990. 212 с.

5. Смирнова О.В. Хронический миелолейкоз - клинические и иммунологические особенности у взрослых больных // Бюллетень Восточно-сибирского научного центра Сибирского отделения Российской академии медицинских наук. 2012. №3 (85). часть 2. С. 185-189. 
6. Смирнова О.В., Манчук В.Т. Особенности прогнозирования возникновения инфекционных осложнений после проведения химиотерапии у больных острыми лейкозами // Медицинская иммунология. 2012. Т14, №4-5. C. $403-408$.

7. Smirnova O.V., Manchouk V.T., Savchenko A.A. Immune status \& enzymes activity in blood lymphocytes in adult patients at different stages of acute lymphoblastic leukaemia. Indian Journal of medical research. 2011. №133, pp. 280-286.

8. Казьмина Н.В. Ферменты метаболизма лимфоцитов у больных раком легкого // Сибирский онкологический журнал. 2008. №51. С. 63-64.

9. Савченко А.А., Сунцова Л.Н. Высокочувствительное определение активности дегидрогеназ в лимфоцитах периферической крови биолюминесцентным методом // Лаб. дело. 1989. № 11. С. 23-25.

10. Савченко А.А., Смирнова О.В., Манчук В.Т., Москов В.И. Способ прогнозирования инфекционных осложнений после химиотерапии у больных острыми лейкозами // Патент на изобретение RUS 2315305 08.11.2005.

11. Савченко А.А., Смирнова О.В., Манчук В.Т., Москов В.И. Способ прогнозирования геморрагических осложнений у больных острыми лейкозами// Патент на изобретение RUS 2324190 15.02.2006.

\section{References}

1. Vasilevskiy M.G., Kamarli Z.P. Statistika i problemy gemoblastozov [Statistics and problems of hemoblastoses]. Vestnik Kyrgyzsko-Rossiyskogo slavyanskogo universiteta [Herald of the Kyrgyz-Russian Slavic University]. 2007. V.7. №9, pp. 84-89.

2. Vorob'ev A.I. Rukovodstvo po gematologii v 3-kh tomakh [Manual on hematology in 3 volumes]. V.1. M.: N'yudiamed. 2002. 280 p.

3. Galstyan G.M., Kesel'man S.A., Gorodetskiy V.M. et al. Sochetannoe provedenie khimioterapii gemoblastozov i terapii ostroy dykhatel'noy nedostatochnosti v reanimatsionnykh usloviyakh [Combined chemotherapy of hemoblastoses and acute respiratory failure in resuscitation conditions]. Terapevticheskiy arkhiv [Therapeutic Archive]. 2009. №12, pp. 37-43.

4. Kovaleva L.G. Ostrye leykozy [Acute leukemia]. M.: Meditsina. 1990. 212 p.

5. Smirnova O.V. Khronicheskiy mieloleykoz - klinicheskie i immunologicheskie osobennosti u vzroslykh bol'nykh [Chronic myeloleukemia - clinical and immunological features in adult patients]. Byulleten'Vostochno-sibirskogo nauchnogo tsentra Sibirskogo otdeleniya Rossiyskoy akademii meditsinskikh nauk [Bulletin of the East Siberian Scientific Center of the Siberian Branch of the Russian Academy of Medical Sciences]. 2012. №3 (85), part 2, pp. 185-189. 
6. Smirnova O.V., Manchuk V.T. Osobennosti prognozirovaniya vozniknoveniya infektsionnykh oslozhneniy posle provedeniya khimioterapii u bol'nykh ostrymi leykozami [Peculiarities of predicting the occurrence of infectious complications after chemotherapy in patients with acute leukemia]. Meditsinskaya immunologiya [Medical Immunology]. 2012. V.14. №4-5, pp. 403-408.

7. Smirnova O.V., Manchouk V.T., Savchenko A.A. Immune status \& enzymes activity in blood lymphocytes in adult patients at different stages of acute lymphoblastic leukaemia. Indian Journal of medical research. 2011. № 133, pp. 280-286.

8. Kaz'mina N.V. Fermenty metabolizma limfotsitov u bol'nykh rakom legkogo [Enzymes of Lymphocyte Metabolism in Patients with Lung Cancer]. Sibirskiy onkologicheskiy zhurnal [Siberian Oncology Journal]. 2008.№51, pp. 63-64.

9. Savchenko A.A., Suntsova L.N. Vysokochuvstvitel'noe opredelenie aktivnosti degidrogenaz $\mathrm{v}$ limfotsitakh perifericheskoy krovi biolyuminestsentnym metodom [Highly sensitive determination of the activity of dehydrogenases in peripheral blood lymphocytes by bioluminescence method]. Lab. Delo [Laboratory work].1989. № 11, pp. 23-25.

10. Savchenko A.A., Smirnova O.V., Manchuk V.T., Moscov V.I. A method for predicting infectious complications after chemotherapy in patients with acute leukemia. Patent for invention RUS 2315305, 08.11.2005.

11. Savchenko A.A., Smirnova O.V., Manchuk V.T., Moscov V.I. A method for predicting hemorrhagic complications in patients with acute leukemia. Patent for invention RUS 2324190, 15.02.2006

\section{ДАННЫЕ ОБ АВТОРАХ}

Смирнова Ольга Валентиновна, д.м.н., профессор, заведующая лабораторией клинической патофизиологии

Федеральное государственное бюджетное научное учреждение "Федеральный исследовательский иентр «Красноярский научный иентр Сибирского отделения Российской академии наук» «Научно-исследовательский институт медииинских проблем Севера» ул. Партизана Железняка, 32, г. Красноярск, 660022, Российская Федерация ovsmirnova71@mail.ru

Манчук Валерий Тимофеевич, член-корреспондент РАН, профессор, доктор медицинских наук, руководитель научного направления Федеральное государственное бюджетное научное учреждение «Федеральный исследовательский иентр «Красноярский научныий 
чентр Сибирского отделения Российской академии наук» "Научно-исследовательский институт медииинских проблем Севера» ул. Партизана Железняка, 32, г. Красноярск, 660022, Российская Федераичи

DATA ABOUT THE AUTHORS

Smirnova Olga Valentinovna, MD, Professor, Head of the Laboratory of Clinical Pathophysiology Scientific Research Institute of Medical Problems of the North 3g, Partizan Zheleznyaka Str., Krasnoyarsk, 660022, Russian Federation ovsmirnova71@mail.ru

Manchuk Valery Timofeevich, Corresponding Member of the Russian Academy of Sciences, Professor, Doctor of Medical Sciences, Head of Research

Scientific Research Institute of Medical Problems of the North 3g, Partizan Zheleznyaka Str., Krasnoyarsk, 660022, Russian Federation 